\title{
Quadriplegia Following Epileptic Seizure : Things to Keep in Mind
}

\author{
Hasan Hüseyin Kozak, M.D., ${ }^{1}$ Zülal Yeșilbudak, M.D., ${ }^{2}$ Lokman Șis̨man, M.D., ${ }^{3}$ Ali Ulvi Uca, M.D. ${ }^{1}$ \\ Department of Neurology, ${ }^{1}$ Meram Faculty of Medicine, Necmettin Erbakan University, Konya, Turkey \\ Deparments of Neurology, ${ }^{2}$ Neurosurgery, ${ }^{3}$ Beyhekim State Hospital, Konya, Turkey
}

People with epilepsy are believed to be at a higher risk of incurring accidental injury than people who do not have seizures. The incidence of injury, either due to seizure or accident as a consequent of seizure is also high and varies from $0.03 \%$ to $3 \%$. The most common injuries are head contusions, lacerations, burns and fractures. In this article, we present a case of quadriplegia after a generalized epileptic seizure.

Key Words : Epilepsy · Injury · Quadriplegia · Rapid sequence intubation.

\section{INTRODUCTION}

Epilepsy is a difficult disease for patients and doctors as it could show up at any time, it disrupts functionality, and it causes accidents and injuries. It is reported in studies that there is an important relationship between epileptic seizures and injuries, individuals with epilepsy are exposed to traumas much more than the normal population and serious injuries develop due to these traumas. Although a normal life is encouraged for individuals with epilepsy, they could be especially dangerous in peri-ictal periods for themselves or others ${ }^{14)}$.

\section{CASE REPORT}

A 55 year old female patient diagnosed with epilepsy and under follow up developed generalized tonic clonic seizure that lasted for 5 minutes. The emergency department team was informed and she was brought to the emergency department. On arriving at the site the emergency team where the patient had the seizure, found her lying in a supin position with a foamy mouth and bitten tongue. A $2 \mathrm{~cm}$ cut was seen at the back of the head most probably as a result of falling and hitting it. The patient was found to have difficulty in breathing and after suction of the mouth, oxygen was administered. The general clinical condition being quite poor and having an apneic respiratory pattern, the patient was immediately intubated. The patient was unconscious with a blood pressure level of $80 / 60 \mathrm{~mm} \mathrm{Hg}$ and pulse count of 66/min. Light reflexes were normal in the patient, there were no verbal and pain responses and the Babinski sign was bilateraly unresponsive. The patient was brought to the hospital by the emergency team in an intubated state and admitted to the neurology intensive care unit. The patient's hematologic and biochemical tests were unremarkable and the carbamazepine levels were found to be $3.8 \mu \mathrm{g} / \mathrm{mL}$ (4-12). The patient had been diagnosed with epilepsy and under follow up for 40 years, had a moderate level of mental retardation, did not use her medical treatment (carbamazepine $800 \mathrm{mg} /$ day) regularly and failed to go for her routine medical checkups. It was also learned that she develops once or twice a month generalized tonic clonic seizures and that during some of these seizures she has suffered small injuries but had not had any fatal trauma or accident. Antiepileptic treatment was started and on the 6th hour of follow up consciousness was regained and flask quadriplegia was seen on neurologic examination. A cervical MRI was taken and a severe spinal cord compression, widespread spinal cord edema and also subluxation at C3-4 were seen due to fracture of the lower back part of $\mathrm{C} 3$ vertebra most probably as a result of trauma (Fig. 1,2). The patient was diagnosed with flask quadriplegia due to cervical fracture. Surgical operation was not recommended by the neurosurgery department because the patient had low arterial blood pressure during her follow-ups, had bradycardia and could not

- Received : March 7, 2015 • Revised : January 8, 2016 • Accepted : January 9, 2016

- Address for reprints : Hasan Hüseyin Kozak, M.D.

Department of Neurology, Meram Faculty of Medicine, Necmettin Erbakan University, Meram, Konya 42080, Turkey

Tel : +90-332 223 7344, Fax : +90-332 263 1245, E-mail : hhkozak@gmail.com

- This is an Open Access article distributed under the terms of the Creative Commons Attribution Non-Commercial License (http://creativecommons.org/licenses/by-nc/3.0) which permits unrestricted non-commercial use, distribution, and reproduction in any medium, provided the original work is properly cited. 


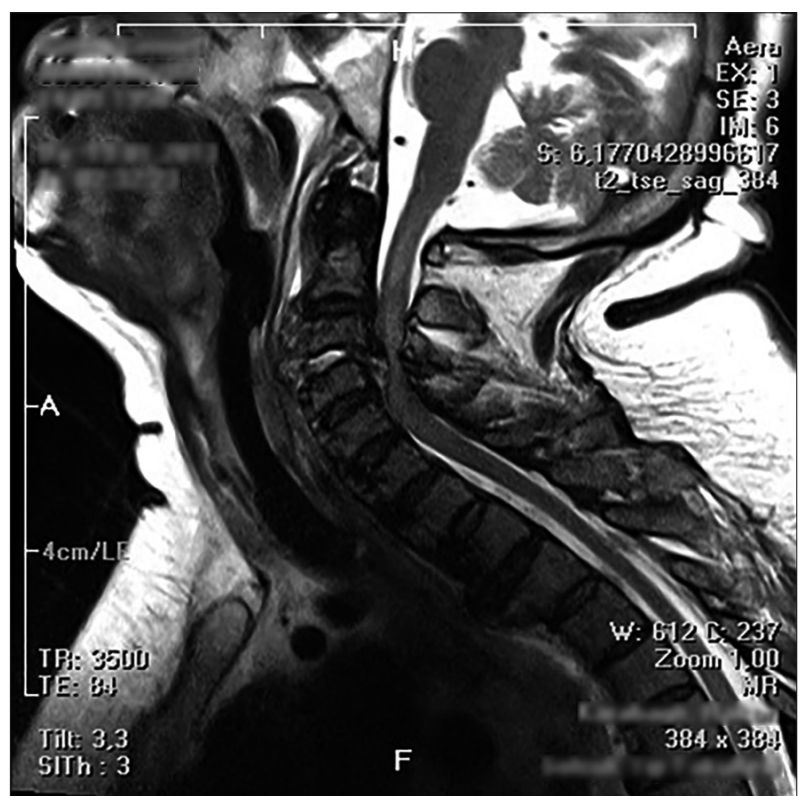

Fig. 1. Severe spinal cord compression, widespread spinal cord edema.

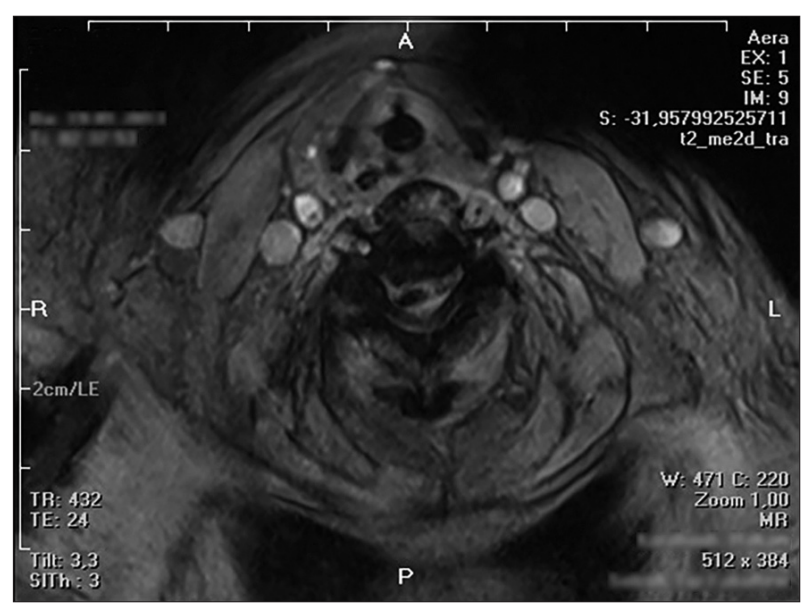

Fig. 2. Subluxation at C3-4 due to fracture of the lower back part of C3 vertebra.

be separated from the mechanical ventilator due to respiratory acidosis. The patient was given pulse steroid therapy. Antiepileptic, inotropic and fluid therapy was administered. The patient died on the 2 nd day of treatment.

\section{DISCUSSION}

Epilepsy is a neurologic disease commonly seen across the world. The disease makes no discrimination in terms of ethnicity, sex and age. The incidence of epilepsy in industrialized countries varies between $20-70 / 100000$. The prevalence of epilepsy in developed countries is estimated to be 6/1000 and with prevalence studies carried out by the World Health Organization protocol this rate is estimated to be $18.5 / 1000$ on average in developing countries. While in all hospital based studies, $65-70 \%$ of newly diagnosed epilepsy patients are taken under control with anti-epileptic drug, seizures persist in approximately $30-35 \%$ in spite of treatment. $20 \%$ of these patients then enter into remission. These are chronic epilepsy patients and their prognoses are commonly not good. Chronic epilepsia also comes with intensive medication use, decrease in cognitive skills, psycho-social dysfunction, disruption of life quality, degradation in morbidity and increase in death rates. It is known that mortality risk is increased in epilepsy compared to non-epileptic individuals and standardized mortality rate is estimated to be multiplied by 2 or $3^{5)}$. While mortality related to seizures is rare in new onset epilepsy, deaths related to seizures are frequent in patients with chronic epilepsy. Studies show that there is a relationship between epilepsy and traumas in that traumas are experienced more and serious injuries develop as a result of these injuries ${ }^{7,14)}$. The incidence of injury, either due to seizure or accident as a consequent of seizure is also high and varies from $0.03 \%$ to $3 \%{ }^{3,7}$. Soft tissue injuries, fractures, teeth injuries, head trauma, traffic accidents, burns and drowning are the most frequently reported accidents related to seizures in individuals with epilepsy ${ }^{8,12)}$.

There are generally, some risk factors increasing injury in individuals with epilepsy. The type and frequency of seizures, side effects of antiepileptic medicines play important roles as risk factors $^{7)}$. A more significant relationship is found between the seizure type and injury risk in previously done studies ${ }^{9,14)}$. Generalized tonic-clonic, atonic and myoclonic seizures carry high risk in terms of injury as they cause the patient to fall by causing loss of consciousness. According to a previous study head injury due to a fall develops in more than half of individuals with epilepsy ${ }^{6}$. Most seizure related fractures result from a fall. However, some fracture-dislocations can result from violent muscle contractions during seizure activity. A number of rare combinations of fractures resulting from the latter mechanism have been reported in the literature ${ }^{10,15)}$. Vertebral fractures are a recognised complication of longstanding epilepsy. These fractures can occur due to violent contractions of the muscles during seizure. Most vertebral fractures occur in the upper and mid-thoracic region and fortunately are inherently stable $e^{3,411)}$. Any patient known to have suffered a seizure with evidence of trauma above the clavicles should be assumed to have suffered a potentially serious cervical spine injury and be immobilised appropriately. A careful neurological examination may reveal signs of spinal cord injury. If doubts remain on the basis of concerning plain radiographs alone, a computed tomography scan to identify bony injury, and a magnetic resonances to identify soft tissue injury should be obtained on an urgent basis. A potential contributing factor in the patient was reduced bone quality because of chronic anti-seizure medication use. It is well documented that patients taking anticonvulsant drugs are at increased risk of osteomalacia and osteopenia as a result of multiple effects of anticonvulsant medication $^{2,13)}$.

As has been discussed, chronic epilepsy patients with irregular checkup and medication use, having damaged bone metabolism due to drug effects and having frequent generalized seizures re- 
sulting in trauma are at a high risk of being fatally wounded. It is quite difficult to determine the reason behind the cervical fracture and the resulting quadriplegia that occurred in this case. Generalized tonic-clonic type of epileptic seizures and the resulting injuries after falling might have caused the series of events that have been discussed earlier on. Furthermore a patient experiencing difficulties in breathing with low vital signs might have this clinic condition arise during intubation. The most important issues in the stabilization of a patient presenting with acute generalized seizure are, with no doubt, airway tract patency, respiration and oxygenation optimization. As well as head position, trismus, tongue blocking the airway, excessive secretion and foreign body aspiration. Respiration depressions related to the treatments are also the situations threatening respiration in a patient having seizures. Besides, the person may experience respiratory insufficiency and may need advanced air tract support due to head-neck traumas, brain edema, intracranial pressure increases etc. that may occur due to trepidation resulted from seizure or indirect reasons. In these patients, early airway tract patency, secretion and foreign body aspiration and cervical stabilization must be enabled at every stage. In case of the need for an advanced patent airway tract, rapid sequence intubation protocol must be adapted considering the existing clinical condition of the patient and the possible associated pathologies ${ }^{11}$.

\section{CONCLUSION}

The fact that individuals with epilepsy experience accidents due to the seizures it is adviced on the need and importance of educating patients and patient relatives in terms of taking precautions to protect epileptic patients from accidents. Besides, close follow-up of patients using long term medicines, increasing the adaptation for the medicine and care of the patient and patient relatives in terms of effects and side effects of the disease are of paramount importance. Management of possible trauma and similar conditions and issues to be considered afterwards also matter very much. The teams evaluating the patients coming to emergency departments as status epilepticus must make an effort to thoroughly investigate the medical history of the patient. We also believe that the awareness of the medical team must be increased with regards to performing of a detailed evaluation of the patients. They should be aware of the complications that might arise due to seizures and seizure related factors and should keep in mind the rapid sequence of intubation when need arises to secure a patent airway.

\section{References}

1. Davis DP, Hoyt DB, Ochs M, Fortlage D, Holbrook T, Marshall LK, et al. : The effect of paramedic rapid sequence intubation on outcome in patients with severe traumatic brain injury. J Trauma 54 : 444-453, 2003

2. Fitzpatrick LA : Pathophysiology of bone loss in patients receiving anticonvulsant therapy. Epilepsy Behav 5 Suppl 2 : S3-S15, 2004

3. Kirby S, Sadler RM : Injury and death as a result of seizures. Epilepsia 36 : 25-28, 1995

4. Kumar SK, Freeman BJ : Quadriplegia following grand mal seizures. Injury 30 : 626-629, 1999

5. Lhatoo SD, Johnson AL, Goodridge DM, MacDonald BK, Sander JW, Shorvon SD : Mortality in epilepsy in the first 11 to 14 years after diagnosis : multivariate analysis of a long-term, prospective, populationbased cohort. Ann Neurol 49 : 336-344, 2001

6. Mollaoğlu M, Bolayır E : Epilepsili hastalarda yaralanmalar ve ilişkili bazı faktörler. Nöropsikiyatri Arşivi 50 : 269-273, 2013

7. Nakken KO, Lossius R : Seizure-related injuries in multihandicapped patients with therapy-resistant epilepsy. Epilepsia 34 : 836-840, 1993

8. Nei M, Bagla R : Seizure-related injury and death. Curr Neurol Neurosci Rep $7: 335-341,2007$

9. Neufeld MY, Vishne T, Chistik V, Korczyn AD : Life-long history of injuries related to seizures. Epilepsy Res 34 : 123-127, 1999

10. Parrish GA, Skiendzielewski JJ : Bilateral posterior fracture-dislocations of the shoulder after convulsive status epilepticus. Ann Emerg Med 14 : 264-266, 1985

11. Pedersen KK, Christiansen C, Ahlgren P, Lund M : Incidence of fractures of the vertebral spine in epileptic patients. Acta Neurol Scand $54: 200$ 203, 1976

12. Russell-Jones DL, Shorvon SD : The frequency and consequences of head injury in epileptic seizures. J Neurol Neurosurg Psychiatry 52 : 659-662, 1989

13. Souverein PC, Webb DJ, Weil JG, Van Staa TP, Egberts AC : Use of antiepileptic drugs and risk of fractures : case-control study among patients with epilepsy. Neurology 66 : 1318-1324, 2006

14. van den Broek M, Beghi E; RESt-1 Group : Accidents in patients with epilepsy : types, circumstances, and complications : a European cohort study. Epilepsia 45 : 667-672, 2004

15. Vanderhooft E, Swiontkowski M : Bilateral femoral neck fractures following a grand mal seizure. Ann Emerg Med 24 : 1188-1191, 1994 